\title{
Synthesis of Fe-Cu Nanoparticles by Mechanochemical Processing Using a Ball Mill *1
}

\author{
Yoshikazu Todaka $^{1, * 2}$, Paul Gerard McCormick ${ }^{2}$, Koichi Tsuchiya ${ }^{1}$ \\ and Minoru Umemoto ${ }^{1}$ \\ ${ }^{1}$ Department of Production Systems Engineering, Toyohashi University of Technology, Toyohashi 441-8580, Japan \\ ${ }^{2}$ Department of Mechanical and Materials Engineering, University of Western Australia, Nedlands, WA 6907, Australia
}

$\mathrm{Fe}-\mathrm{Cu}$ nanoparticles were synthesized by mechanochemical processing, which utilizes the reaction of $\mathrm{FeCl}_{3}$ and $\mathrm{CuCl}_{2}$ with $\mathrm{Na}$ during ball milling. Morphologies, structures and magnetic properties of the synthesized nanoparticles were investigated. The crystallite size and mean particle size of the washed nanoparticles after $84 \mathrm{~h}$ milling were approximately $9 \mathrm{~nm}$ and $50 \mathrm{~nm}$, respectively. During ball milling, the crystallite size remained constant at approximately $14 \mathrm{~nm}$, while the particle size increased. The elemental mapping images of Fe and Cu by imaging filter revealed that the synthesized nanoparticles were a solid solution of the $\mathrm{Fe}-\mathrm{Cu}$ system. It was seen that numerous hexagonal plates of $\mathrm{Fe}(\mathrm{OH})_{2}$ exist in the washed nanoparticles. The plates had a few nm in thickness and a few hundreds nm in diameter. The coercivity of the synthesized Fe-Cu nanoparticles after $48 \mathrm{~h}$ milling was as high as $33.5 \mathrm{kA} / \mathrm{m}$. This is because the particle is close to the critical size for a single magnetic domain of $\alpha$-Fe.

(Received November 22, 2001; Accepted February 6, 2002)

Keywords: iron-copper solid solution, non-equilibrium phase, nanoparticle, mechanochemical reaction, ball mill, microstructure, magnetic property

\section{Introduction}

Mechanochemical processing makes use of enhancement of chemical reactions by mechanical energy. Ding and coworkers $^{1-8)}$ have synthesized a number of metallic and oxide nanoparticles, such as $\mathrm{Fe}, \mathrm{Cu}, \mathrm{Co}, \mathrm{Ni}, \mathrm{Fe}_{2} \mathrm{O}_{3}, \mathrm{Cr}_{2} \mathrm{O}_{3}$ and $\mathrm{Al}_{2} \mathrm{O}_{3}$, by mechanochemical processing using a ball mill. In the present study, this method has been applied to synthesize nanoparticles of non-equilibrium $\mathrm{Fe}-\mathrm{Cu}$ solid solution by the simultaneous progress of the following two reactions:

$$
\begin{aligned}
& \mathrm{FeCl}_{3}+3 \mathrm{Na} \rightarrow \mathrm{Fe}+3 \mathrm{NaCl} \\
& \mathrm{CuCl}_{2}+2 \mathrm{Na} \rightarrow \mathrm{Cu}+2 \mathrm{NaCl}
\end{aligned}
$$

The $\mathrm{Fe}-\mathrm{Cu}$ binary system possesses a large positive enthalpy of mixing and thus is virtually immiscible in the whole range of composition in equilibrium. A solid solution of the $\mathrm{Fe}-$ $\mathrm{Cu}$ system can be obtained only by non-equilibrium techniques, such as mechanical alloying ${ }^{9,10}$ or vapor deposition. ${ }^{11)}$ The reactions (1) and (2) result in the formation of $\mathrm{Fe}-\mathrm{Cu}$ nanoparticles embedded in the matrix of by-product $\mathrm{NaCl}$. Provided that the volume fraction of $\mathrm{NaCl}$ is sufficiently large, the metal nanoparticles separately nucleate and grow in the $\mathrm{NaCl}$ matrix. In this study, the volume fraction of $\mathrm{NaCl}$ in the product mixture is calculated to be $95.8 \mathrm{vol} \%$. Subsequent removal of the $\mathrm{NaCl}$ results in the powder consisting of nanometer sized particles. $\mathrm{NaCl}$ powder also has another important role to suppress combustive reaction during the milling. In the previous investigations, ${ }^{1-4)}$ $\mathrm{Fe}$ and $\mathrm{Cu}$ nanoparticles were synthesized through the reactions (1) and (2), respectively, and these reactions proceed with unstable self-propagating combustion due to the large

\footnotetext{
${ }^{* 1}$ This Paper was Presented at the Autumn Meeting of the Japan Institute of Metals, held in Kanazawa, on November 20, 1999.

${ }^{* 2}$ Graduate Student, Toyohashi University of Technology.
}

enthalpy changes in the reactions $\left(\Delta H_{293 \mathrm{~K}}=-834 \mathrm{~kJ}\right.$ for (1), $\Delta H_{293 \mathrm{~K}}=-604 \mathrm{~kJ}$ for (2)). ${ }^{12)}$ The combustive reaction is undesirable for the synthesis of nanoparticles since it causes a significant temperature rise, leading to a larger particle size. Therefore, the suppression of the combustive reaction is important for the synthesis of uniform sized nanoparticles in this process. The previous studies suggested that the combustion reaction could be initiated by ball/powder collision events during milling. ${ }^{1-5,13,14)}$ Reduction of collision energy and dilution of reactants are considered as the possible means for avoiding combustive reaction. In this study, the combustive reaction was suppressed by adding $\mathrm{NaCl}$ powder into the starting mixture, to decrease the collision frequency between the reactants.

This paper describes the results of a study on the evolution of nanostructures and magnetic properties during the mechanochemical processing of $\mathrm{FeCl}_{3}$ and $\mathrm{CuCl}_{2}$ with $\mathrm{Na}$ to form $\mathrm{Fe}-\mathrm{Cu}$ nanoparticles. It was also found that the formation of thin hexagonal plates of $\mathrm{Fe}(\mathrm{OH})_{2}$ accompanies the $\mathrm{Fe}-$ $\mathrm{Cu}$ nanoparticles formation.

\section{Experimental Procedure}

\subsection{Synthesis of nanoparticles}

The starting materials used in this study were anhydrous $\mathrm{FeCl}_{3}(>98 \%), \mathrm{CuCl}_{2} \cdot \mathrm{H}_{2} \mathrm{O}(>99 \%)$ powders and $\mathrm{Na}$ blocks $(<5 \mathrm{~mm}) . \mathrm{NaCl}(>99.5 \%)$ powder was added as a diluent to the starting mixture in order to avoid combustive reaction. The chloride powders were dried prior to milling. The starting mixture $(5 \mathrm{~g})$, that consists of $\mathrm{FeCl}_{3}+\mathrm{CuCl}_{2}+5 \mathrm{Na}+7 \mathrm{NaCl}$, was loaded and sealed together with $\phi 4.8 \mathrm{~mm}$ steel balls ( $15 \mathrm{~g})$ in a hardened steel vial under Ar atmosphere. The reactants were milled using a SPEX 8000 mixer/mill for various times (up to $84 \mathrm{~h}$ ). The vial temperature was kept constant by air-cooling. The outside temperature of the vial was mon- 
itored during the course of milling using a Chromel-Alumel thermocouple attached to its surface. An abrupt increase of the vial temperature indicates that the combustive reaction occurred. In this study, all the milling processes were carried out without the combustive reaction. The $\mathrm{Fe}-\mathrm{Cu}$ nanoparticles were separated from $\mathrm{NaCl}$ through a following washing process. The as-milled powders were dispersed ultrasonically in the deionized and deoxygenated water. Then, the $\mathrm{Fe}-\mathrm{Cu}$ particles and $\mathrm{NaCl}$ solution were separated using a magnet or a centrifuge. After washing, the $\mathrm{Fe}-\mathrm{Cu}$ particles were dried under vacuum at room temperature and directly transferred to a glove box filled with Ar.

\subsection{Characterization of nanoparticles}

Structure analysis of the washed powders was carried out on a Siemens 5000 X-ray diffractometer with Ni-filtered $\mathrm{Cu}-$ $\mathrm{K}_{\alpha}$ radiation generated at $40 \mathrm{kV} / 35 \mathrm{~mA}$. A sealed and Ar filled sample holder was used to prevent oxidation of the sample.

Compositions of the washed powders were analyzed on a JEOL JSM-6300 scanning electron microscope (SEM) equipped with an energy dispersive X-ray spectroscope (EDX). The analysis was carried out on a sampling area of $200 \mu \mathrm{m} \times 160 \mu \mathrm{m}$. Morphologies of the washed powders were observed on a JEOL 6300F field emission SEM (FESEM). Both SEM and FESEM investigations were performed at an acceleration voltage of $20 \mathrm{kV}$.

Morphologies, nanostructures and compositions of the washed powders were investigated on an analytical transmission electron microscopy (TEM) using a Philips 430 equipped with a Gatan Imaging Filter GIF200 incorporated in an electron energy loss spectroscope (EELS) for elemental mapping at an acceleration voltage of $300 \mathrm{kV}$. A sample holder in which sample could be sealed was used, so that the sample was set up in the TEM without exposure to air. The synthesized nanoparticles were put onto a carbon film supported on a copper grid directly from the washed powder, and then the grid was loaded to the sample stage in the glove box. These investigations were also done on a highresolution TEM (HRTEM) using a JEOL JEM-2010 equipped

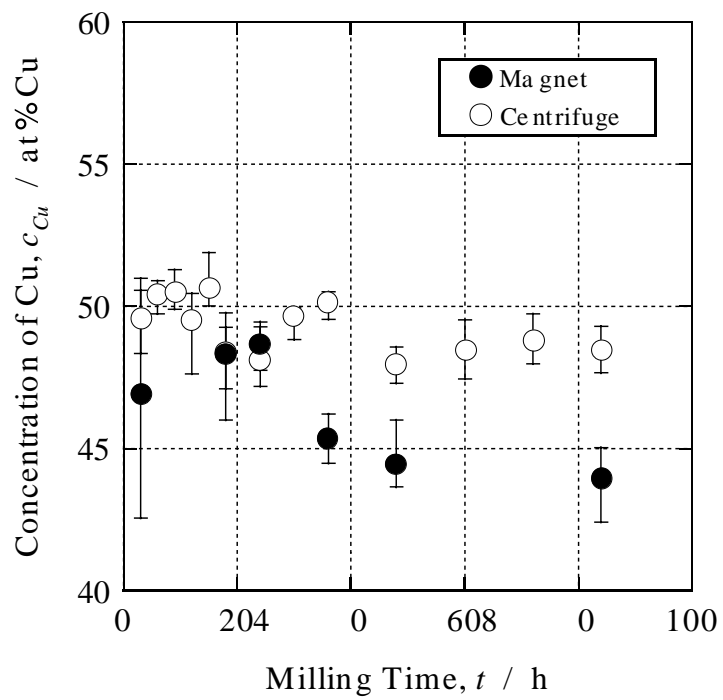

Fig. 1 Compositions of the washed powders for various milling times. The error bars indicate the maximum and minimum values of 5 sampling points. with a NORAN Voyager III EDX at an acceleration voltage of $200 \mathrm{kV}$. Nanobeam diffraction (NBD) mode on the JEM-2010 was used to obtain electron diffraction patterns from individual nanoparticles. The synthesized nanoparticles were dispersed ultrasonically in iso-propyl alcohol, and a few drops of the mixture were then pipetted onto a $\mathrm{Ni}$ grid just before insertion into the JEM-2010 TEM, thus minimizing the possibility of oxidation in air.

Specific surface areas of the washed powders were measured with the five-points BET (Brunauer-Emmett-Teller) method using a Micromeritics Gemini 2360. Mean diameters of particles were estimated from the specific surface area.

Magnetic measurements of the as-milled powders were carried out on an Oxford 3001 vibrating sample magnetometer (VSM) with a maximum applied field of $2.4 \mathrm{MA} / \mathrm{m}$ at room

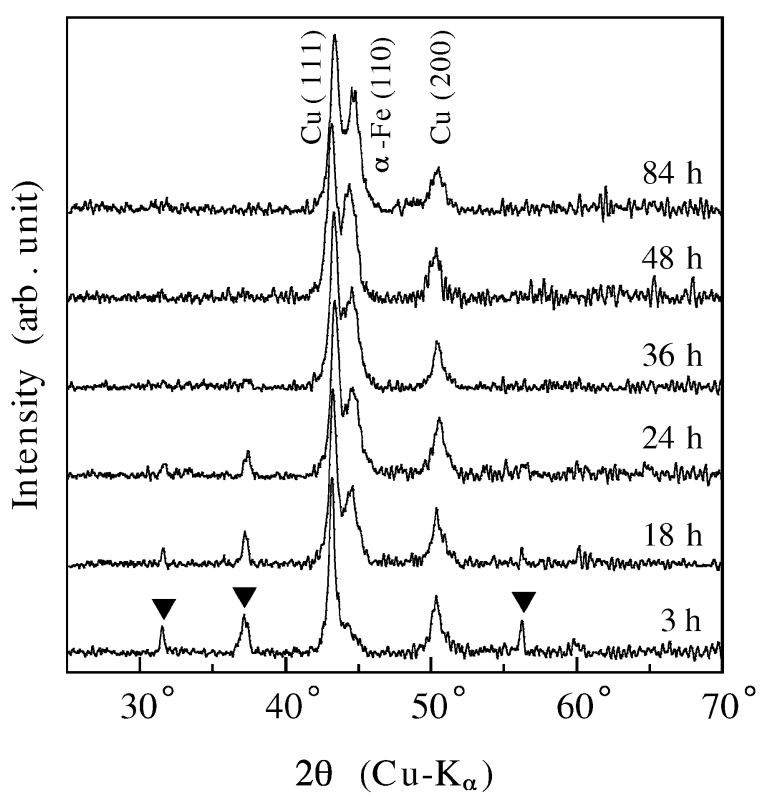

Fig. 2 XRD patterns of the washed powders for various milling times. The triangles denote the peaks are from the hexagonal plates (see text).

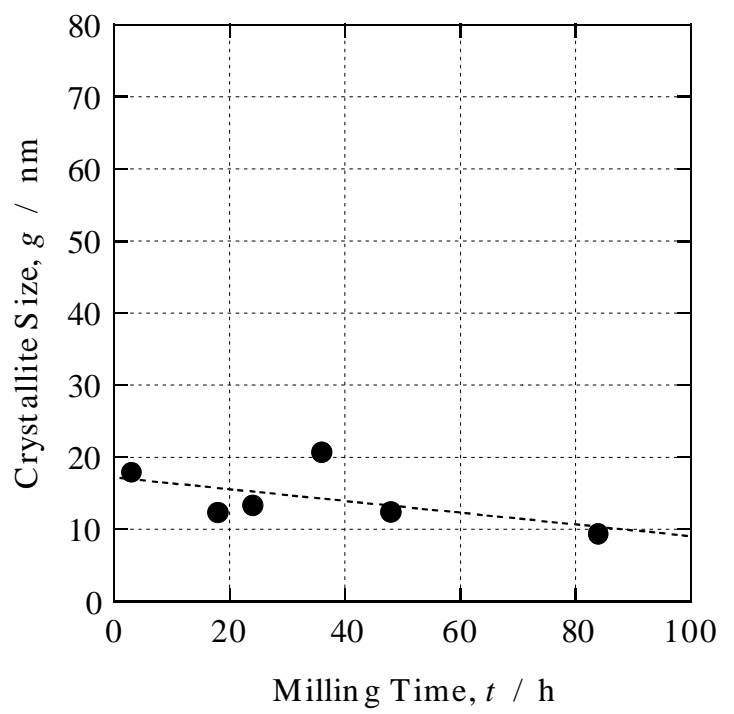

Fig. 3 Crystallite sizes of the washed nanoparticles for various milling times, which estimated from the width of the $\mathrm{Cu}$ (200) peak in the XRD patterns (Fig. 2). 
temperature. The as-milled powders were cold-pressed to the shape of cylinder $(\phi 5 \mathrm{~mm} \times t 3.5 \mathrm{~mm})$ in a glove box. The pressed samples were sealed and fixed in a polymer vial using wax. Magnetization at the maximum field of $2.4 \mathrm{MA} / \mathrm{m}$ was taken to be the saturation magnetization.

\section{Results and Discussion}

Figure 1 reveals the compositions of the washed pow-
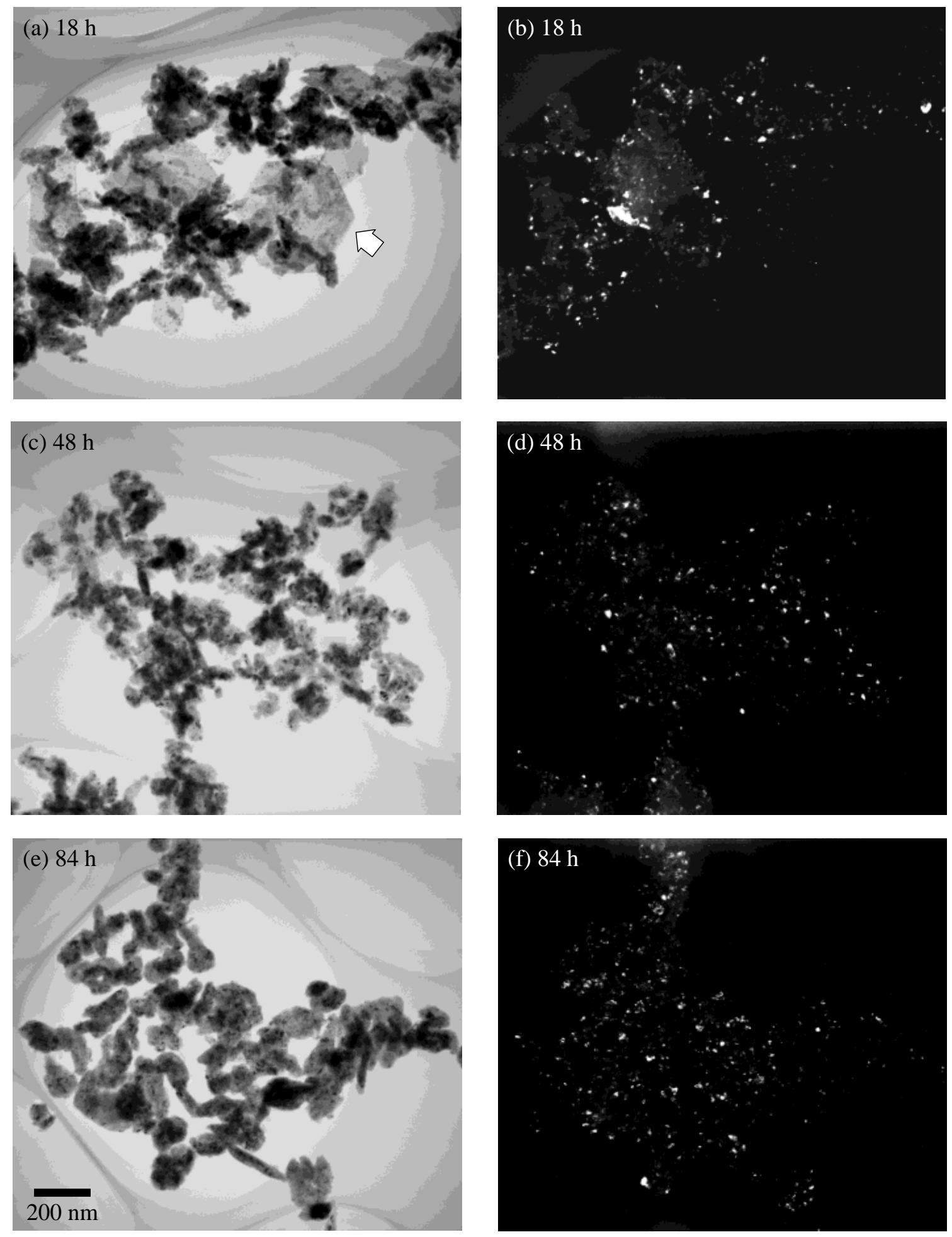

Fig. 4 TEM BF images ((a), (c) and (e)) and DF images ((b), (d) and (f)) of the washed powders for various milling times. The arrow denotes the hexagonal plate.

ders for various milling times, analyzed using the EDX in the SEM. The average composition of the powders collected by using a magnet was approximately $\mathrm{Fe}-46.3 \mathrm{at} \% \mathrm{Cu}$, slightly deficient in $\mathrm{Cu}$ than the nominal composition ( $\mathrm{Fe}-$ $50.0 \mathrm{at} \% \mathrm{Cu}$ ). On the other hand, the average composition of the powders collected by a centrifuge was approximately $\mathrm{Fe}-$ 49.3 at $\% \mathrm{Cu}$, closer to the nominal composition. It is due to that the synthesized $\mathrm{Cu}$-rich particles could not be collected completely by using a magnet, because Fe clusters in the fcc-
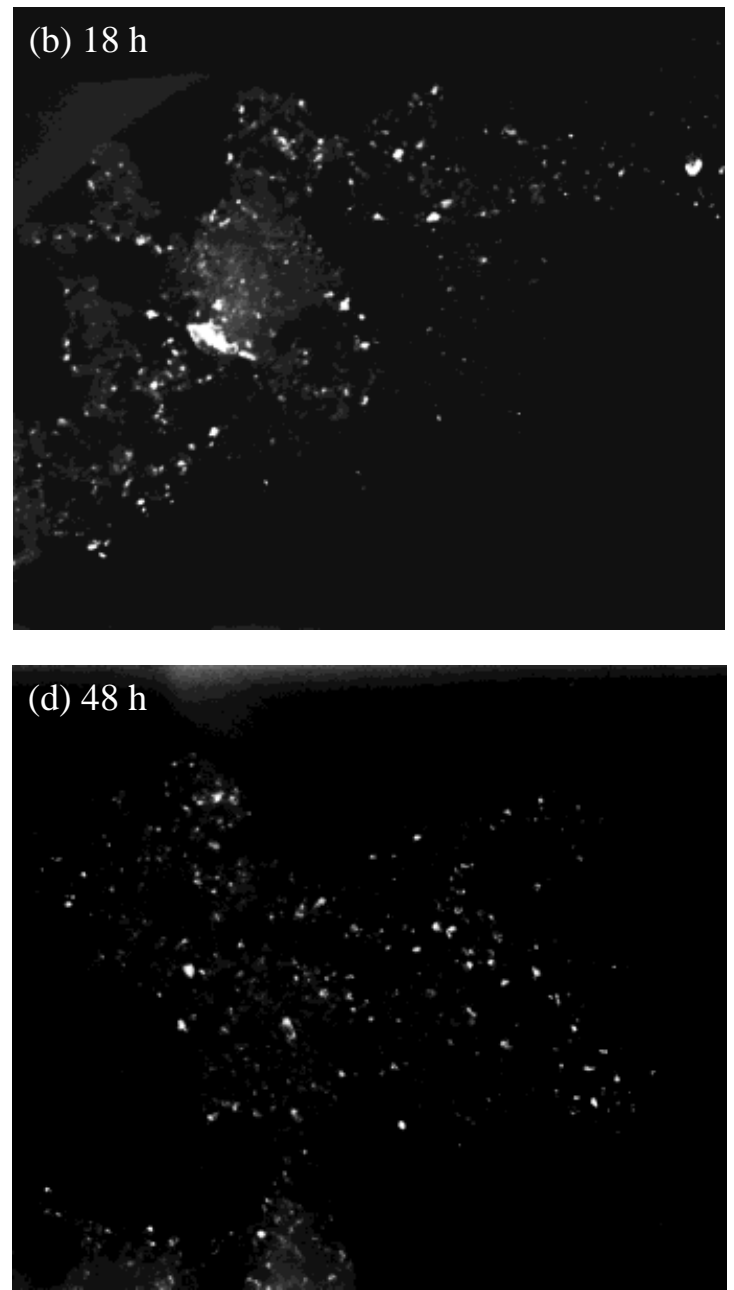
$\mathrm{Cu}$ matrix behave as $\gamma-\mathrm{Fe},{ }^{11,15)}$ in which the magnetic moment of $\mathrm{Fe}$ atoms is extremely small. The powders collected using a centrifuge, however, were exposed to air in the course of collecting, leading to the oxidation of the $\mathrm{Fe}-\mathrm{Cu}$ nanoparticles.

Figure 2 reveals the X-ray diffraction (XRD) patterns of the washed powders for various milling times. The peaks corresponding to bcc and fcc phases could be identified provided that the lattice parameters of bcc and fcc phases were close to those of $\alpha-\mathrm{Fe}$ and $\mathrm{Cu}$, respectively. It can be seen that $\mathrm{Fe}$ and $\mathrm{Cu}$ particles are obtained after removing the remaining reactants and $\mathrm{NaCl}$ by the appropriate washing process. In the XRD patterns, the peaks other than those of $\mathrm{Fe}$ and $\mathrm{Cu}$, denoted by the triangles in Fig. 2, are found for the powders milled for shorter time $(<24 \mathrm{~h})$. Those peak positions were close to those of $\mathrm{Fe}(\mathrm{OH})_{2}$ (hexagonal, $a=0.32800 \mathrm{~nm}$, $c=0.460500 \mathrm{~nm}){ }^{16)}$

The crystallite sizes of the washed $\mathrm{Fe}-\mathrm{Cu}$ nanoparticles were estimated using the Scherrer equation from the width of the $\mathrm{Cu}(200)$ peak in the XRD patterns. ${ }^{17)}$ Figure 3 reveals

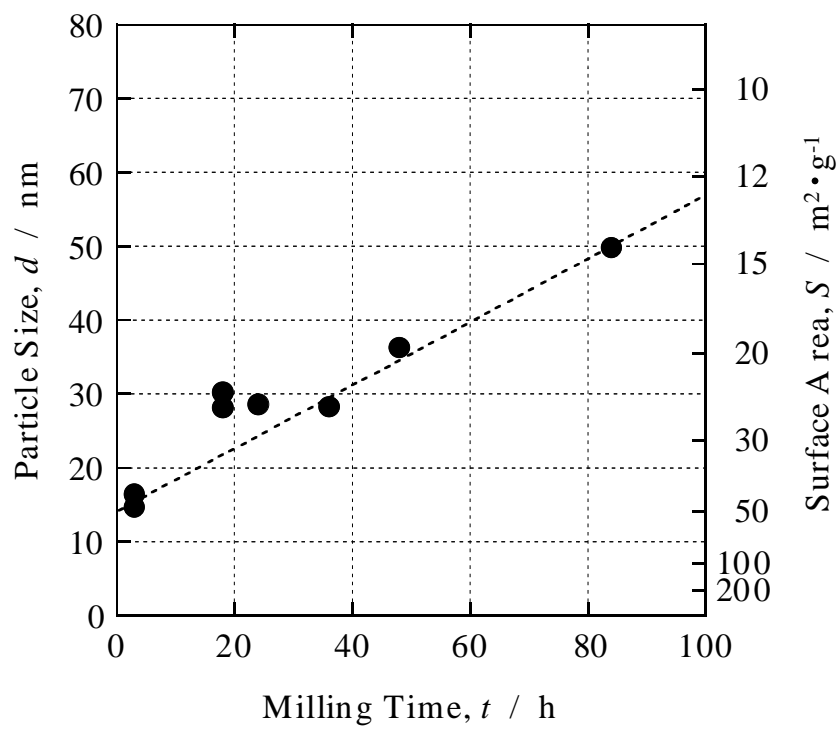

Fig. 5 Particle sizes of the washed powders for various milling times. the crystallite sizes of the washed nanoparticles for various milling times. The correction of the machine error was carried out with the Warren's method, ${ }^{17)}$ using $\mathrm{Cu}$ powder with the purity of $99.999 \%$ and the particle size of $150 \mu \mathrm{m}$ as the standard sample. The crystallite size of $\mathrm{Cu}$ was approximately $14 \mathrm{~nm}$, and remained constant with milling time. The crystalline size was also estimated by TEM observations.

Figure 4 shows the TEM images (bright field (BF), (a), (c) and (e), and dark field (DF), (b), (d) and (f)) of the washed $\mathrm{Fe}-\mathrm{Cu}$ nanoparticles after $18 \mathrm{~h}, 48 \mathrm{~h}$ and $84 \mathrm{~h}$ milling. In the DF images, the strongly reflecting regions corresponded to the rings of $\alpha-\mathrm{Fe}$ (110) or $\mathrm{Cu}$ (111). The DF images show that there is no remarkable difference in the crystalline size of $\mathrm{Fe}$ and $\mathrm{Cu}$, and therefore it is suggested that both sizes are approximately $14 \mathrm{~nm}$ with the $\mathrm{Cu}$ crystallite size estimated from the XRD peak widths. The crystalline size remained constant with milling time, which was in good agreement with the crystallite size (Fig. 3).

Figure 5 reveals the mean particle sizes estimated from the specific surface areas of the washed powders for various milling times. The particle size increased with milling time, to be approximately $16 \mathrm{~nm}$ and $50 \mathrm{~nm}$ for powders milled for $3 \mathrm{~h}$ and $84 \mathrm{~h}$, respectively. These results were also in good agreement with those estimated from the TEM BF images shown in Fig. 4. Nevertheless, the particle size remains in the order of ten nanometers. It is inferred from these results that the by-product of $\mathrm{NaCl}$ successfully suppressed the welding between particles during milling.

In the washed powder for $18 \mathrm{~h}$ milling shown in Fig. 4(a), two kinds of morphologies were observed, an irregular and a hexagonal shape denoted by the arrow. The FESEM images also show such morphologies in Fig. 6. The washed powder for $18 \mathrm{~h}$ milling included the numerous hexagonal plates in comparison with the powder for $48 \mathrm{~h}$ milling. The plates are generally with a thickness of a few nanometers and a diameter of approximately $300 \mathrm{~nm}$ in the powder milled for $18 \mathrm{~h}$. Although the mean particle size increased linearly with milling time (Fig. 5), the size deviation reached a maximum around $18 \mathrm{~h}$ milling. It is attributed to that the washed powder milled for around $18 \mathrm{~h}$ included the numerous hexagonal plates.

Figure 7 shows the TEM BF, and elemental mapping im-
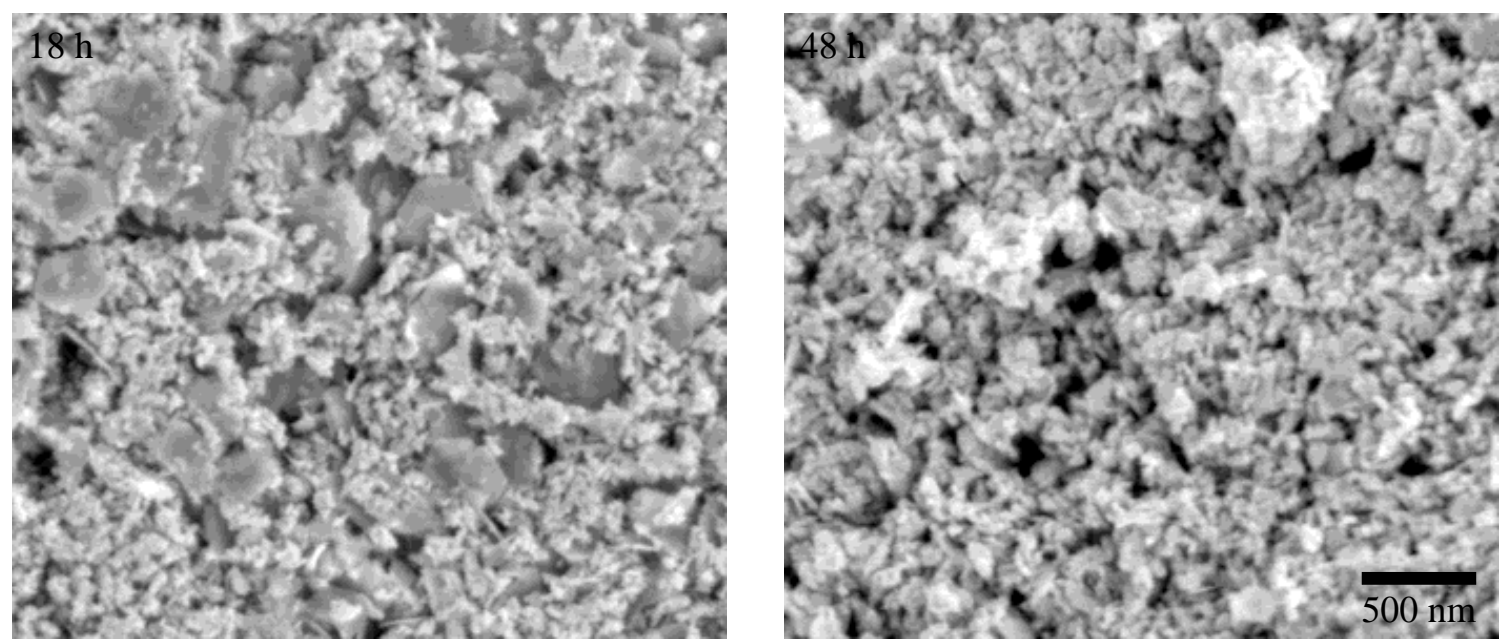

Fig. 6 FESEM images of the washed powders after $18 \mathrm{~h}$ and $48 \mathrm{~h}$ milling. 


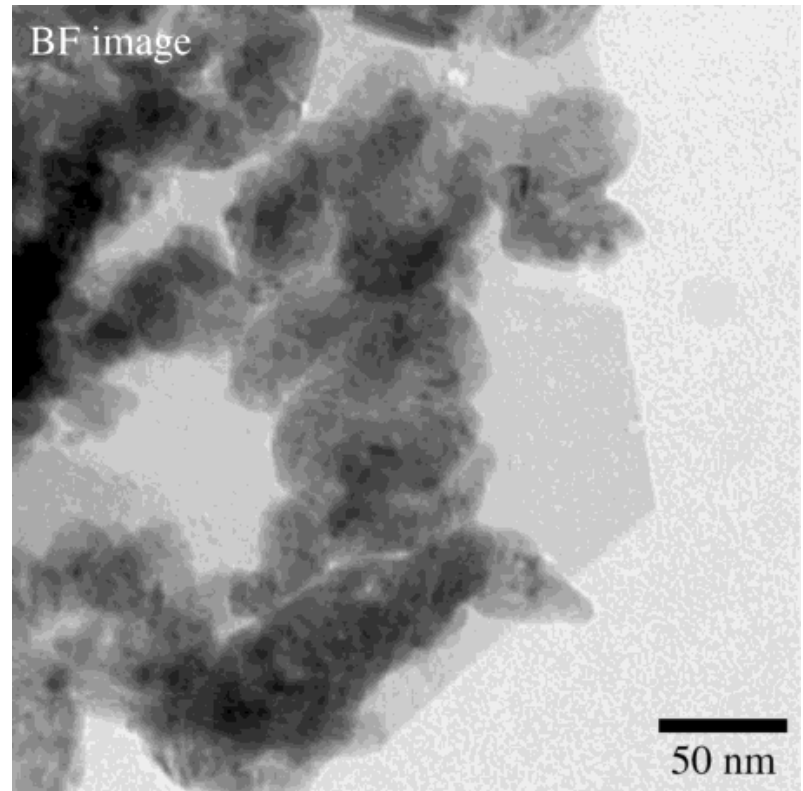

(a)
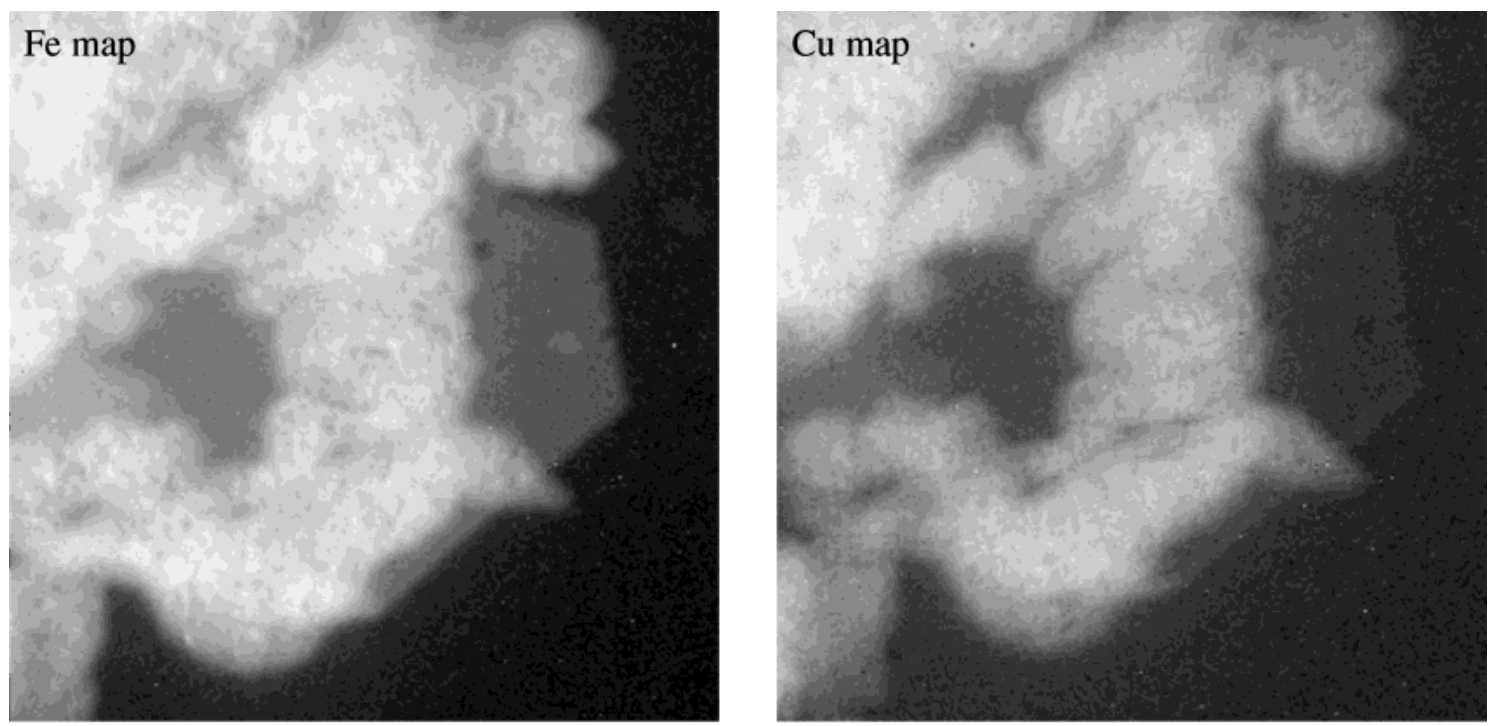

(b)

Fig. 7 TEM BF (a) and elemental mapping (b) images of the washed powder after $48 \mathrm{~h}$ milling.

ages of $\mathrm{Fe}$ and $\mathrm{Cu}$ using the imaging filter for the washed powder after $48 \mathrm{~h}$ milling. In the mapping images, the signal from both $\mathrm{Fe}$ and $\mathrm{Cu}$ can be seen in the whole area of the particles, suggesting that the nanoparticles are a solid solution of the $\mathrm{Fe}-\mathrm{Cu}$ system. The mapping images also exhibit mottled contrasts due to the non-uniformity in the composition. The size of the contrast is smaller than the crystallite size (about $14 \mathrm{~nm}$ ) determined by XRD pattern and the grain size determined by TEM DF image. Also the mapping images show that the hexagonal plate does not contain $\mathrm{Cu}$ atoms because the signal from $\mathrm{Cu}$ can hardly be seen.

The structure and composition of the hexagonal plate in the washed powder milled for $18 \mathrm{~h}$ were investigated using the HRTEM with the EDX, as are shown in Fig. 8. The NBD pattern and the EDX spectrum from the area enclosed with a circle in the TEM BF image (Fig. 8(a)) are shown in
Figs. 8(b) and (c), respectively. The NBD pattern suggests that the hexagonal plates are $\alpha-\mathrm{Fe}_{2} \mathrm{O}_{3}$ with [001] normal, and the EDX spectrum exhibited only Fe peaks (Ni peaks were confirmed to be from a Ni grid). Figure 9 also shows the HRTEM image and the NBD pattern of the hexagonal plate in the washed powder milled for $84 \mathrm{~h}$. The lattice space was $0.24 \mathrm{~nm}$, which was close to the reference value of $\alpha-\mathrm{Fe}_{2} \mathrm{O}_{3}$ $\{200\}$ plane $\left(0.25178 \mathrm{~nm}^{18)}\right)$. It is therefore suggested that the hexagonal plates are $\alpha-\mathrm{Fe}_{2} \mathrm{O}_{3}$ with [001] normal. However, the XRD patterns (Fig. 2) indicated that the hexagonal plates are $\mathrm{Fe}(\mathrm{OH})_{2}$. These results suggested that $\mathrm{Fe}(\mathrm{OH})_{2}$ was transformed into $\alpha-\mathrm{Fe}_{2} \mathrm{O}_{3}$ by iso-propyl alcohol that was used to disperse the synthesized nanoparticles in the TEM observations. The mechanism for the formation of the hexagonal plates has not been clarified yet. In the previous study of Fe nanoparticles synthesis with the reaction (1), however, these 

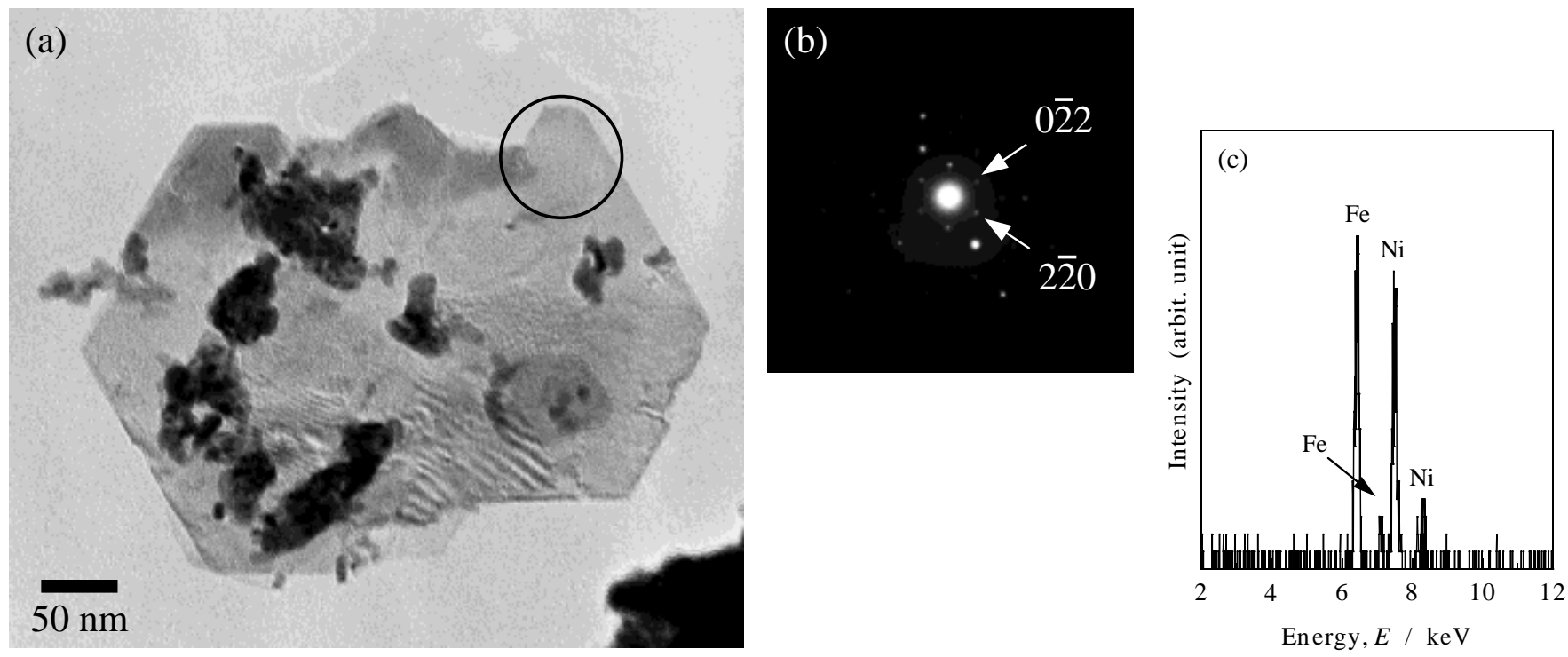

Fig. 8 TEM BF image (a), NBD pattern (b) and EDX spectrum (c) of the hexagonal plate in the washed powder after $18 \mathrm{~h}$ milling.
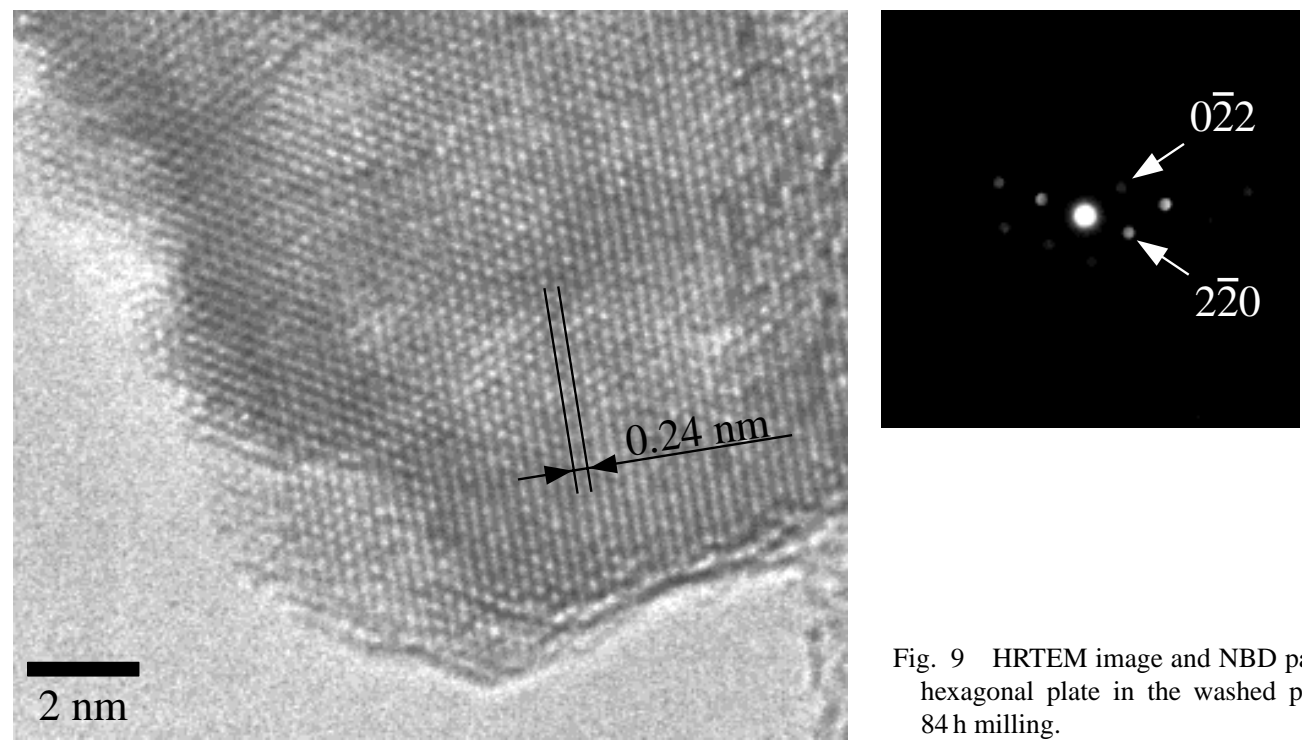

Fig. 9 HRTEM image and NBD pattern of the hexagonal plate in the washed powder after $84 \mathrm{~h}$ milling.

hexagonal plates were not found, ${ }^{1-3)}$ suggesting that the existence of $\mathrm{Cu}$ catalyzed the formation of the plates. Also, $\mathrm{Fe}(\mathrm{OH})_{2}$ plates seem to form in the course of washing because $\mathrm{Fe}(\mathrm{OH})_{2}$ contains two hydroxyl radicals. The plates may be synthesized as a result of the reaction of water and iron ions in the colloid consisting of the remaining reactants and $\mathrm{Fe}-\mathrm{Cu}$ nanoparticles.

Figure 10 reveals the saturation magnetization $\left(M_{S}\right)$ and coercivity $\left(H_{C}\right)$ values of the as-milled powders for various milling times. The $M_{S}$ values increase rapidly with milling time in the first $18 \mathrm{~h}$ milling, and levels off upon further $(>18 \mathrm{~h})$. The maximum $M_{S}$ value was approximately $15.9 \mu \mathrm{Wb} \cdot \mathrm{m} / \mathrm{kg}$, which was smaller than the calculated $M_{S}$ of $18.3 \mu \mathrm{Wb} \cdot \mathrm{m} / \mathrm{kg}$ for the mixture $\mathrm{Fe}+\mathrm{Cu}+12 \mathrm{NaCl}$. It is because the $\mathrm{Fe}$ clusters in the fcc- $\mathrm{Cu}$ matrix behave as $\gamma$ $\mathrm{Fe}$ phase, ${ }^{11,15)}$ in which the magnetic moment of $\mathrm{Fe}$ atoms is extremely small. The progress of the reaction (1) during milling was inferred to nearly complete after $18 \mathrm{~h}$ milling from the change of the $M_{S}$ value, for the reason that the bcc-
Fe phase is ferromagnetic with a $M_{S}$ of $270 \mu \mathrm{Wb} \cdot \mathrm{m} / \mathrm{kg}$ at room temperature while the magnetizations of $\mathrm{FeCl}_{3}, \mathrm{CuCl}_{2}$, $\mathrm{Na}$ and $\mathrm{Cu}$ are negligibly small. In addition, the result of the composition analysis (Fig. 1) indicated that the reactions (1) and (2) progressed simultaneously, because the compositions of the synthesized $\mathrm{Fe}-\mathrm{Cu}$ nanoparticles for various milling times were always close to the nominal composition (Fe50.0 at $\% \mathrm{Cu}$ ). The $H_{C}$ value increased with milling time in the first $48 \mathrm{~h}$ milling, then further milling caused the decrease of the $H_{C}$ values. The maximum $H_{C}$ value was approximately $33.5 \mathrm{kA} / \mathrm{m}$. This value is much higher than that of the bulk $\alpha$ $\mathrm{Fe}$ (about $0.1 \mathrm{kA} / \mathrm{m}$ ). It is attributed to that the particle size is close to the critical size for a single magnetic domain particle of Fe, which is $20-40 \mathrm{~nm}^{19,20)}$

\section{Conclusion}

$\mathrm{Fe}-\mathrm{Cu}$ nanoparticles synthesized by a mechanochemical processing using a ball mill and a subsequent washing pro- 


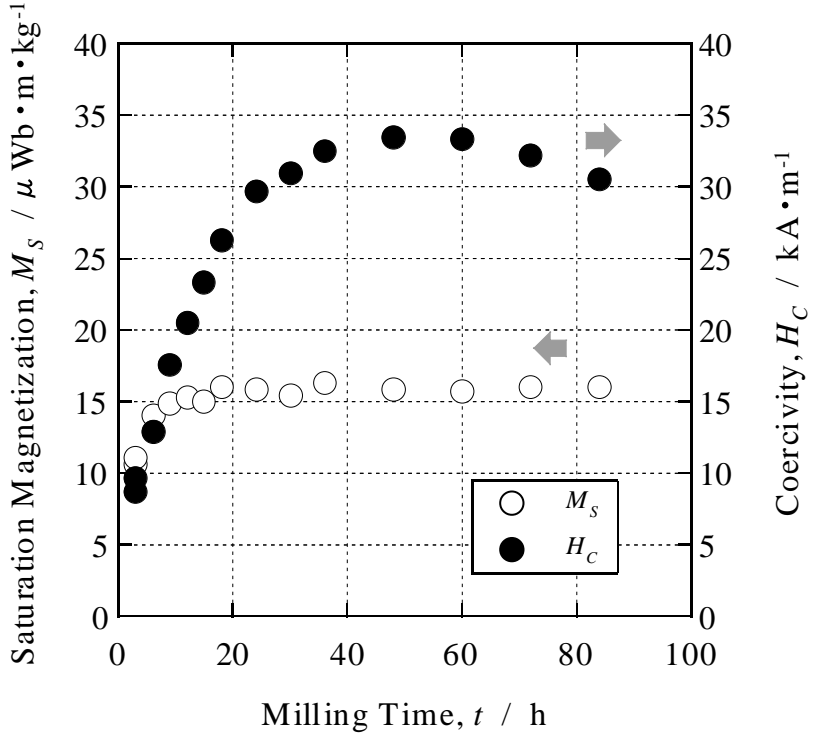

Fig. 10 Saturation magnetization, $M_{S}$, and coercivity, $H_{C}$, values of the as-milled powders for various milling times.

cess were found to be a solid solution of the $\mathrm{Fe}-\mathrm{Cu}$ system. The particle size was uniform and approximately $50 \mathrm{~nm}$ after $84 \mathrm{~h}$ milling. The crystallite size remained constant as approximately $14 \mathrm{~nm}$ with milling time. Numerous thin hexagonal plates of $\mathrm{Fe}(\mathrm{OH})_{2}$ are also synthesized. The coercivity of approximately $33.5 \mathrm{kA} / \mathrm{m}$ after $48 \mathrm{~h}$ milling was found to be much higher than that of the bulk Fe. This can be attributed to the nanometer size of the particles.

\section{REFERENCES}

1) J. Ding, W. F. Miao, T. Tsuzuki, P. G. McCormick and R. Street: Synthesis and Processing of Nanocrystalline Powder, ed. by D. L. Bouvell (TMS, 1996) pp. 69-79.

2) J. Ding, W. F. Miao, P. G. McCormick and R. Street: Appl. Phys. Lett. 67 (1995) 3804-3806.

3) J. Ding, T. Tsuzuki, P. G. McCormick and R. Street: J. Magn. Magn. Mater. 162 (1996) 271-276.

4) J. Ding, T. Tsuzuki, P. G. McCormick and R. Street: J. Alloys Comp. 234 (1996) L1-L3.

5) J. Ding, T. Tsuzuki, P. G. McCormick and R. Street: J. Phys. D 29 (1996) 2365-2369.

6) J. Ding, T. Tsuzuki and P. G. McCormick: Nano Structured Materials 8 (1997) 739-747.

7) T. Tsuzuki and P. G. McCormick: Acta Mater. 48 (2000) 2795-2801.

8) J. Ding, T. Tsuzuki and P. G. McCormick: J. Am. Ceram. Soc. 79 (1996) 2956-2958.

9) J. Eckert, J. C. Holzer, C. E. Krill III and W. L. Johnson: J. Appl. Phys. 73 (1993) 2794-2802.

10) L. B. Hong and B. Fultz: Acta Mater. 46 (1998) 2937-2946.

11) K. Sumiyama, T. Yoshitake and Y. Nakamura: J. Phys. Soc. Jpn. 53 (1984) 3160-3165.

12) I. Brain: Thermochemical Data of Pure Substance (Weinheim, Germany: VCH, 1995).

13) G. B. Schaffer and P. G. McCormick: Metall. Trans. A 23 (1992) 12851290.

14) H. Yang and P. G. McCormick: J. Mater. Sci. Lett. 12 (1993) 10881091.

15) Y. Ueda, S. Ikeda, Y. Mori and H. Zaman: Mater. Sci. Eng. A 217/218 (1996) 371-375.

16) JCPDS card, 13-0089.

17) B. D. Cullity: Elements of X-ray diffraction, (Addison-Wesley, 1978).

18) JCPDS card, 33-0664.

19) W. Gong, H. Li, Z. Zhao and J. Chen: J. Appl. Phys. 69 (1991) 51195121

20) N. Hiratsuka, H. Tomimori, T. Minakawa and K. Kakizaki: J. Jpn Soc. Powder Metall. 43 (1996) 1411-1414. 